
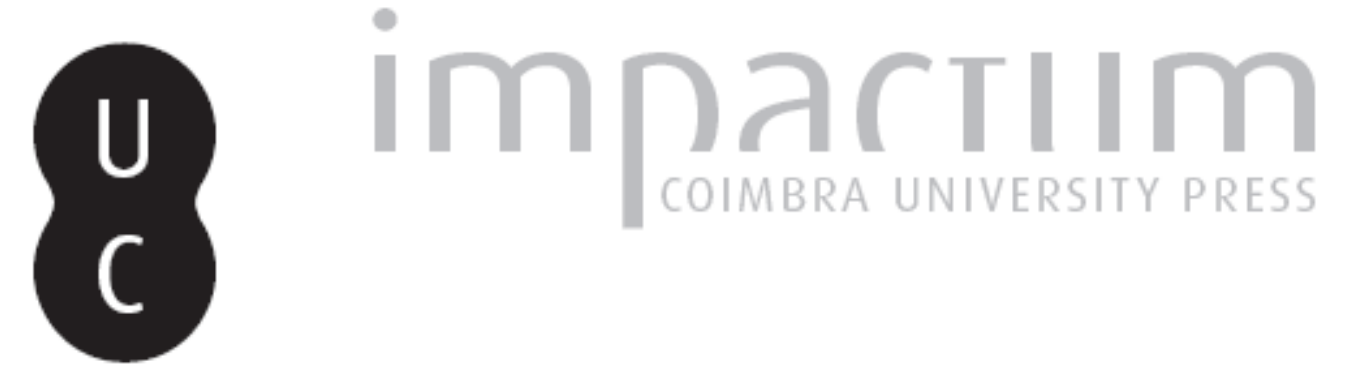

\title{
Modelação da erosão do solo e sua verificação numa área florestal recentemente ardida ęm Açores, Centro-Norte de Portugal
}
Autor(es):
Vieira, Diana
D. C.
C. S.; Malvar, M.
M. C.; Nunes, J. P.; Keizer, J. J
Publicado por: Associação Portuguesa de Riscos, Prevenção e Segurança
URL
persistente:
URI:http://hdl.handle.net/10316.2/36102
DOI:
DOI:http://dx.doi.org/10.14195/1647-7723_17_13
Accessed :
26-Apr-2023 11:43:46

A navegação consulta e descarregamento dos títulos inseridos nas Bibliotecas Digitais UC Digitalis, UC Pombalina e UC Impactum, pressupõem a aceitação plena e sem reservas dos Termos e Condições de Uso destas Bibliotecas Digitais, disponíveis em https://digitalis.uc.pt/pt-pt/termos.

Conforme exposto nos referidos Termos e Condições de Uso, o descarregamento de títulos de acesso restrito requer uma licença válida de autorização devendo o utilizador aceder ao(s) documento(s) a partir de um endereço de IP da instituição detentora da supramencionada licença.

Ao utilizador é apenas permitido o descarregamento para uso pessoal, pelo que o emprego do(s) título(s) descarregado(s) para outro fim, designadamente comercial, carece de autorização do respetivo autor ou editor da obra.

Na medida em que todas as obras da UC Digitalis se encontram protegidas pelo Código do Direito de Autor e Direitos Conexos e demais legislação aplicável, toda a cópia, parcial ou total, deste documento, nos casos em que é legalmente admitida, deverá conter ou fazer-se acompanhar por este aviso.

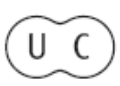




\section{territorium}

Riscos, Sociedade(s) e Segurança

Revista da Associação Portuguesa de Riscos, Prevenção e Segurança 2010 
Diana D. C. S. Vieira*

dianac.s.vieira@ua.pt

M. C. Malvar *

maruxa@ua.pt

J. P. Nunes *

jpcn@ua.pt

J. J Keizer *

jjkeizer@ua.pt.

* Centro de Estudos do Ambiente e do Mar (CESAM), Departamento de Ambiente e Ordenamento, Univ. de Aveiro

\section{RESUMO}

O presente trabalho tem como objectivo avaliar a adequabilidade de dois modelos empíricos de erosão, para o mapeamento do risco de erosão pós-fogo à escala da encosta, com base em Sistemas de Informação Geográfica. Foi desenvolvido no âmbito do projecto EROSFIRE, que pretende avaliar as vantagens e desvantagens de experiências de campo de simulação de chuva para mapear o risco de erosão, fornecendo dados necessários à calibração de modelos.

Palavras-chave: fogos florestais, erosão do solo, mapeamento.

\section{RÉSUMÉ}

Cette étude vise à évaluer l'adéquation de deux modèles empiriques d'érosion, de la cartographie du risque d'érosion dans la situation post-incendie, à l'échelle de pente, sur la base des systèmes d'information géographique. L'étude a été développée dans le champ d'application du projet EROSFIRE, qui vise à évaluer les avantages et les inconvénients de l'expérience de terrain sur la simulation des précipitations pour la carte des risques d'érosion, en fournissant les données nécessaires pour l'étalonnage du modèle.

Mots-clé: feux de forêt, érosion du sol, la cartographie

\section{ABSTRACT}

This study aims to assess the suitability of two empirical erosion models, for mapping the risk of erosion in post-fire situation at slope-scale, based on Geographical Information Systems. It was developed within the scope of EROSFIRE project, which aims to evaluate the advantages and disadvantages of field rainfall experiences, to map the risk of erosion, by providing required data for model calibration.

Key words: forest fires, soil erosion, mapping

$1{ }^{*} \mathrm{O}$ texto deste artigo corresponde à comunicação apresentada ao $\mathrm{V}$ Encontro Nacional e I Congresso Internacional de Riscos e foi submetido para revisão em 28-07-2009, tendo sido aceite para publicação em 31-03-2010.

Este artigo é parte integrante da Revista Territorium, n. ${ }^{\circ} 17,2010$, @ Riscos, ISBN: 0872- 8941. 


\section{Introdução}

Os ecossistemas mediterrâneos estão adaptados a incêndios florestais recorrentes, no entanto, a actividade humana elevou significativamente a frequência de incêndios na Península Ibérica, em grande parte devido à plantação homogénea de florestas comerciais (Puigdefábregas, 1998). Os fogos florestais podem causar alterações significativas nos processos hidrológicos e erosivos, através da destruição do coberto vegetal e alterações nas propriedades do solo, provocando aumentos notáveis do escoamento superficial, caudais de ponta e taxas de erosão hídrica (p.e. SHAKESBY E DoERr, 2006). Porém, a resposta hidrológica e de erosão pós-fogo constitui, em muitas partes do mundo, uma preocupação importante devido às suas implicações em termos de sustentabilidade de uso do solo, por um lado, e, por outro, aos seus possíveis efeitos a jusante na bacia hidrográfica como, por exemplo, inundações e assoreamento de barragens (LARSEN E MACDONALD, 2007). Assim, previsões fidedignas de perdas de solo após incêndios florestais assumem uma importância para orientar a tomada de decisões relativamente à gestão pós-fogo e às necessidades de monitorização dos eventuais processos hidrológicos e de erosão (LARSEN E MACDONALD, 2007).

No seguimento dos verões de 2003 e 2005 com as suas ocorrências dramáticas de incêndios florestais, as taxas de erosão pós-fogo foram, de facto, previstas para Portugal continental (INAG, 2003, 2005). A base desta previsão assenta na Equação Universal para as Perdas de Solo (USLE; Wischmeier e SMith, 1978). Trata-se de um modelo empírico que foi originalmente desenvolvido para áreas agrícolas nas Estados Unidos de América. A sua aplicabilidade em áreas florestais recentemente ardidas em Portugal, no entanto, nunca foi verificada através de medições de campo. Assim surgiu como um dos principais objectivos do projecto EROSFIRE ( $\mathrm{POCl} /$ AGR/60354/2004) a verificação da USLE para condições pós-fogo. Um outro objectivo do referido projecto é a avaliação simultânea de outros, mais modernos, modelos de erosão do solo. Um dos modelos escolhidos é o do Morgan-Morgan-Finney (MMF, Morgan, 2001). Este retém as vantagens de uma abordagem empírica no que toca a simplicidade conceitual, facilidade de cálculo e requisitos de dados de entrada mas tem uma base física mais consolidada do que a USLE, incluindo alguns dos novos avanços neste tema desde a criação do USLE.

O objectivo principal deste trabalho é avaliar a adequabilidade dos modelos de erosão do solo USLE e MMF, para o mapeamento do risco de erosão pós-fogo à escala da encosta usando um Sistema de Informação Geográfica (SIG). Para este fim, as previsões destes dois modelos são comparadas com três tipos de medições do campo: 1) simulações de chuva; 2) parcelas de erosão à escala de encostas; 3) inventários de fenómenos de erosão visíveis.

\section{Materiais e Métodos}

\section{Área de Estudo}

O local de estudo encontra-se perto de localidade de Açores que pertence ao concelho de Albergaria-a-Velha (Fig.1). Esta área foi afectada por um incêndio florestal em Julho de 2005 que cobriu aproximadamente uma área de 270 hectares.

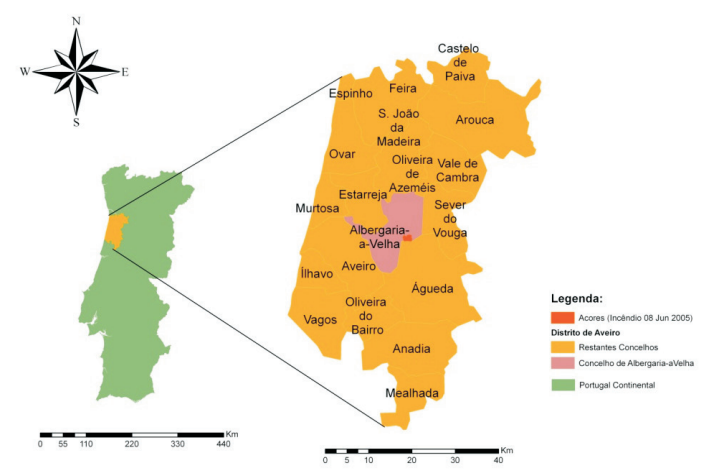

Fig. 1 - Localização geográfica da área de estudo relativamente ao Distrito e Concelho (Adaptado de Carta Administrativa, Atlas do Ambiente Digital - Instituto do Ambiente, 2008).

O clima da área de estudo caracteriza-se como húmido meso-térmico, com um período de verão longo, quente e seco (Csb, segundo KöPPEN, DRA-CENTRO, 1998). A precipitação anual é na ordem dos 1200-1400 mm.

O tipo de solo é Leptossolo Dístrico ou Úmbrico (FAO, 1988), dependente no horizonte A. Estes solos são desenvolvidos sobre xistos e possuem uma textura franco-arenosa com elevada matéria orgânica $(8,8$-10,4 \%) (LUCENA, 2006).

A ocupação do solo na altura do incêndio consistia predominantemente de eucaliptais (aproximadamente $85 \%$ ), com práticas de preparação do terreno variadas como, por exemplo, socalcos e lavragem em contornos, tal como se pode verificar nas fotografias aéreas antes do incêndio.

\section{Simulações de chuva}

Durante o primeiro ano após o incêndio foram realizadas várias campanhas de simulações de chuva em duas encostas adjacentes dentro da área de estudo: Açores 1, eucaliptal ardido sem intervenção, e Açores 2, eucaliptal ardido com lavragem pré-fogo no sentido do declive. As simulações de chuva foram realizadas com um simulador portátil segundo CERDÁ et al., (1997), 
mas com algumas alterações relativamente ao desenho original, nomeadamente: i) parcelas quadradas de 0,28 $\mathrm{m} 2$ em vez de circulares; ii) duas intensidade de chuva, o standard de 40-45 mm h-1 e um de 80-85 mm h-1. Como justificação destas duas intensidades, pode-se referir que a primeira corresponde à chuva horária máxima da estação de Caramulo para um período de retorno de 100 anos, e a segunda ao máximo alguma vez registado em Portugal (BRANDÃo et al., 2001).

As três campanhas de campo foram executados em Setembro 2005, Março e Abril de 2006. Cada campanha envolveu quatro simulações em cada uma das duas encostas (duas de 40-45 mm h-1) e duas de 80-85 $\mathrm{mm}$ h-1), e cada simulação envolveu uma duração de uma hora, durante o qual a escorrência foi medida em intervalos de um minuto e recolhida em até cinco amostras. No laboratório, a concentração de sedimentos das amostras de escorrência foram analisadas usando métodos standard.

\section{Parcelas de erosão}

$\mathrm{Na}$ base de cada uma das duas encostas referidas anteriormente, Açores-ms1 e Açores-ms2, foram instaladas, em Setembro de 2005, quatro parcelas de erosão abertas. Cada parcela consistia de uma saída igual às das parcelas das simulações de chuva, com uma largura máxima de aproximadamente $50 \mathrm{~cm}$, que estava ligada, através de uma mangueira, a um ou mais tanques de 60 litros para a recolha de água de escorrência. O conteúdo destes tanques foi, em caso de chuva, medido e amostrado semanalmente. As amostras foram analisadas da mesma maneira que as amostras da água de escorrência das simulações de chuva. Para o actual estudo foi contemplado o período de monitorização de Outubro de 2005 até Setembro de 2006, correspondendo ao ano hidrológico após o incêndio. Simultaneamente à monitorização das parcelas de erosão também foi registada a precipitação, através de um pluviómetro automático e dois pluviómetros totalizadores.

\section{Inventário de fenómenos de erosão}

A partir da cartografia topográfica à escala 1.10.000 existente, fornecida pela Câmara Municipal de Albergaria-a-Velha, da carta de solos de Portugal à escala 1:1.000.000 (Atlas do Ambiente, 2008) e de imagens de satélite do local pré (Google Earth) e pós-fogo (Virtual Earth), foram identificados e mapeados os nove tipos/ classes de gestão florestal mencionados no QUADRo I. Esta classificação tem como base as várias intervenções realizadas no local antes ou depois de ocorrer o incêndio. Verificando-se que cerca de $17 \%$ da área havia sido intervencionada recentemente (após o incêndio) e que elevada parte dessas intervenções refere-se a grandes mobilizações de solo associadas à implementação de terraços (13\%).

É de referir também que devido ao tratamento de cartografia a área ardida de 270 ha foi reduzida a 113 há pela exclusão de linhas de água, vias de comunicação e áreas com usos de solo diferente de eucalipto.

De acordo com a percentagem de área associada a cada classe determinou-se o número de amostragens a fazer no local, excluindo-se classes menos relevantes ( $\leq 1 \%)$. Posteriormente, as diferentes áreas foram inventariadas aleatoriamente dentro de cada classe segundo a área mínima para a realização de transectos, isto é, de 25 $\mathrm{m}$ de largura por $40 \mathrm{~m}$ de comprimento, resultando na amostragem de 25 encostas pelas diferentes classes apresentadas (QuADRo I).

O inventário de fenómenos erosivos foi realizado em duas fases. A primeira fase constitui a descrição de fenómenos erosivos superiores, como ravinas, zonas de deposição e raízes (de árvores e arbustos) expostas. Os fenómenos presentes foram registados num esquema geral da encosta e, no caso das ravinas, as suas dimensões foram medidas em 25 encostas da área de estudo.

Verificou-se na primeira fase que, devido a falhas de interpretação de imagens e erros de cartografia, algumas encostas necessitariam de uma reclassificação, mas, de forma a não interromper o plano de trabalho de campo, a segunda fase do inventário foi realizada em apenas 13 das 25 encostas estudadas, nas que se apresentavam correctamente classificadas.

A segunda fase do inventário diz respeito a fenómenos de pormenor, onde se verificou a presença de pedestais, indícios de escorrência e mobilização do solo como acumulações de matéria orgânica. Em cada encosta, este inventário envolveu um transecto de cinco pontos, distribuídos de forma equidistante entre a base e o topo, em cada um dos quais se procedeu a uma descrição pormenorizada do coberto do solo usando uma grelha de $1 \mathrm{~m}$ por $1 \mathrm{~m}$ divido em 100 células de $5 \mathrm{~cm}$ por $5 \mathrm{~cm}$. É de referir também que o inventário permitiu determinar alguns dos parâmetros dos modelos como coberto de solo e alturas das copas das árvores.

\section{Modelação com USLE}

A Equação Universal de Perdas de Solo (WischmeIer E SMITH, 1978) calcula a perda do solo anual (A) através do produto de cinco factores: $i$ ) erosividade da precipitação (R); ii) erodibilidade do solo (K); iii) o factor topográfico (TC); iv) o factor de coberto vegetal (C); v) o factor de práticas de conservação $(\mathrm{P})$. 


$$
A=R \times K \times L S \times C \times P
$$

Sendo:

$$
\begin{aligned}
& \text { A:Perda de solo estimada por ano }[\text { tha.ano }] \\
& \text { R:Indice de erosividade }[\text { MJ.mm/h.Ha.ano }] \\
& K \text { : Indice de erodibilidade }[\mathrm{t} . \mathrm{h} / \mathrm{MJ} . \mathrm{mm}] \\
& L S: \text { Factor topográfico } \\
& \text { C : Factor de coberto vegetal } \\
& P \text { : Factor de prácticas de conservação do solo }
\end{aligned}
$$

\begin{tabular}{|c|c|c|c|c|c|c|c|}
\hline $\begin{array}{l}\text { Cóliso } \\
\text { classe }\end{array}$ & $\begin{array}{l}\text { Intervençăo } \\
\text { poss-fogo }\end{array}$ & $\begin{array}{l}\text { Técrica } \\
\text { Aplicada }\end{array}$ & Geologia & $\begin{array}{l}\text { Area total } \\
\text { (ha) } \\
\text { (ha) }\end{array}$ & Área (\%) & $\begin{array}{l}\text { Nümero } \\
\text { parcelas }\end{array}$ & $\begin{array}{c}\text { Número } \\
\text { amostracos }\end{array}$ \\
\hline${ }_{\mathrm{A} 1}$ & \multirow{4}{*}{$\begin{array}{c}\text { com } \\
\text { Intervençäo }\end{array}$} & Lavrado & xistos & 0,15 & $<1$ & 1 & 1 \\
\hline A2 & & Não & Xistos & 4,49 & 4 & 12 & 2 \\
\hline A3 & & \multirow{2}{*}{ Terraços } & $\begin{array}{c}\text { Rochas } \\
\text { sedimentares } \\
\text { post-Paleozóicas }\end{array}$ & 0,57 & 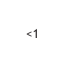 & 2 & 1 \\
\hline A4 & & & Xistos & 12,23 & 11 & 15 & 4 \\
\hline A5 & \multirow{5}{*}{$\begin{array}{c}\text { Sem } \\
\text { Intervençăo }\end{array}$} & \multirow{2}{*}{ Lavrado } & $\begin{array}{l}\text { Rocchas } \\
\text { sedimentares }\end{array}$ & 1,11 & 1 & 3 & 0 \\
\hline A6 & & & xistos & 14,92 & 13 & 22 & 4 \\
\hline A7 & & \multirow{2}{*}{\begin{tabular}{|l} 
Não \\
Perceptivel
\end{tabular}} & $\begin{array}{c}\text { Rochas } \\
\text { sedimentares } \\
\text { post-Palezzócas }\end{array}$ & 13,84 & 12 & 17 & 5 \\
\hline$A B$ & & & Xistos & 57,59 & 51 & 77 & 8 \\
\hline A9 & & Terracos & Xistos & 0,67 & 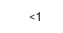 & 1 & 0 \\
\hline \multirow[t]{2}{*}{10} & Verificar & Verificar & Xistos & 6,98 & 6,20 & 14 & \\
\hline & Total Geral & & & 112,56 & 100 & 164 & 25 \\
\hline
\end{tabular}

QUADRo I - Classificação segundo intervenção, técnica agrícola aplicada e geologia associada a cada unidade de gestão florestal

O modelo e os seus dados de entrada encontram-se descritos na Eq.1. O factor $\mathrm{R}$ foi calculado usando os dados do pluviómetro automático na área de estudo. Para cada evento chuvoso durante o período de estudo foram determinados a energia cinética, $\mathrm{o} \mathrm{I}_{30}$ e o factor da erosividade da precipitação.

$\mathrm{O}$ factor $\mathrm{K}$ foi obtido pela metodologia proposta por WischmeIER E SMith (1978), tendo como base a textura e conteúdo de matéria orgânica de várias amostras do solo recolhidas no âmbito do projecto EROSFIRE. Como o local apresentou altos teores de matéria orgânica ( $>4 \%)$, não foi possível determinar o valor de $\mathrm{K}$ pelo ábaco de WISCHMEIER E SMITH (1978), aplicando-se então a fórmula proposta pelos mesmos autores. 0 factor LS foi calculado com base nos declives e comprimento de encosta de cada parcela florestal. Ambos os parâmetros foram determinados, de forma semi-automática, em ArcGIS 9.2.

O factor C foi determinado como o valor indicado por PIMENTA (1999) para áreas ardidas.

Para o factor $\mathrm{P}$ foram adoptados os valores da FAO, conforme a existência ou não de plantação em faixas ou terraços.

\section{Modelação com MMF}

Comparativamente ao anterior, o MMF tem muitos mais parâmetros de entrada, o que implica que, por falta desses mesmos, exista a necessidade de utilizar dados por outras fontes.

Os parâmetros de entrada do modelo podem ser agregados segundo cinco grupos (Fig.2):

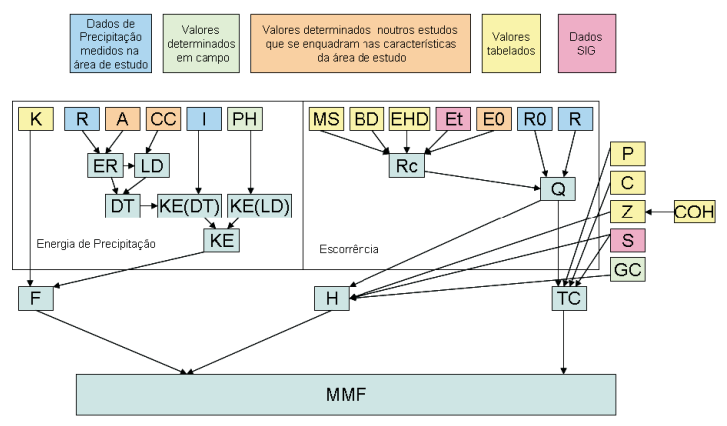

Fig. 2 - Parâmetros de entrada e origem dos dados do modelo MMF.

- Os dados de precipitação medidos no local dos quais depende a determinação da energia de precipitação (KE) e formação de escorrência (Q).

- Também outros dados determinados no campo através da medição da altura das copas das árvores $(\mathrm{PH})$ e fracção de cobertura vegetal (GC) que foram estimados aquando o inventário de fenómenos erosivos.

- Relativamente aos valores determinados noutros estudos que se enquadram nas características da área de estudo, que dizem respeito à fracção de Intercepção (A), à densidade das copas das árvores (CC) por FERREIRA (1996) e ainda a Evapotranspiração potencial segundo os dados do Instituto de Meteorologia de Portugal para o ano agrícola de 2005/2006 (SANTO, 2006). A justificação para estes valores não terem sido determinados na área de estudo deveu-se à complexidade que envolve a determinação destes mesmos.

- No que toca aos valores tabelados segundo o modelo de Morgan (2001) surgem valores empíricos como o factor $C$ e o $P$, que também se aplicam ao USLE (já mencionados), e também parâmetros propostos pelo autor, como é o caso da Profundidade Efectiva do Solo (EHD), da Erodibilidade do solo (K), da Capacidade de Campo de Conteúdo Hídrico (BD) e ainda a Coesão do Solo $(\mathrm{COH})$, que foram obtidos segundo a classe de textura determinada.

- Por fim, foram determinados os dados de entrada com base em cartografia com dados de 30 anos como é o caso da Evapotranspiração total (Et) e ainda o declive da área de estudo. 
Resultados

\section{Simulações de Chuva e Parcelas Abertas}

Os dados resultantes das simulações de chuva e das parcelas abertas foram analisados e comparados em termos de escorrência e taxas de erosão. Para existir uma melhor comparabilidade entre os métodos utilizados, os resultados das simulações de chuva realizadas em Açores-ms1 e Açores-ms2, em cada micro-parcela foram somados e ponderados de acordo com a quantidade de precipitação ocorrida no local.

Pela observação do QUADRo II verifica-se que, segundo as parcelas abertas e as simulações de alta intensidade, ambos os locais apresentam taxas de escorrência semelhantes. Quando se comparam os resultados obtidos pelos dois métodos, as simulações de chuva apresentam taxas de escorrência substancialmente mais elevadas.

QUADRo II - Taxas de escorrência medidas por parcelas abertas e por simulações de chuva em Açores-ms1 e Açores-ms2

\begin{tabular}{cccc}
\hline Locais & $\begin{array}{c}\text { Escorrência parcelas } \\
\text { abertas }\end{array}$ & \multicolumn{3}{|c|}{$\begin{array}{c}\text { Escorrência totais simulaçōes de chuva (mm/mm } \\
\text { precipitaçăo) }\end{array}$} \\
& $(\mathrm{mm} / \mathrm{mm}$ precipitação) & Alta & Standard \\
\hline Açores-ms1 & 0,012 & 0,496 & 0,608 \\
Açores-ms2 & 0,011 & 0,497 & 0,278 \\
\hline
\end{tabular}

Na comparação das taxas de erosão segundo as parcelas abertas e as simulações standard verifica-se que, tal como no caso anterior, não existem diferenças significativas entre as encostas, exceptuando um pico das taxas de erosão em Açores-ms1 para simulações de alta intensidade, mas com valores de escorrência muito semelhantes a Açores-ms2. Novamente os resultados das simulações de chuva apresentam maiores taxas de erosão.

QUADRO III - Taxas de erosão medidas por parcelas abertas e por simulações de chuva em Açores-ms1 e Açores-ms2

\begin{tabular}{cccc}
\hline Locais & $\begin{array}{c}\text { Taxas de Erosăo } \\
\text { parcelas abertas ( } g / 2 \\
\mathrm{~m}^{2} \text {.mm precipitaçăo) }\end{array}$ & Taxas de Erosăo totais simulaçōes de chuva $\left(\mathrm{g} / \mathrm{m}^{2} \cdot \mathrm{mm}\right.$ \\
precipitaçăo) & Alta & Standard \\
\hline Açores-ms1 & 0,002 & 0,288 & 0,082 \\
Açores-ms2 & 0,004 & 0,054 & 0,044 \\
\hline
\end{tabular}

\section{Modelação à escala de encosta}

Procedeu-se à modelação das taxas de erosão para Açores-ms1 e Açores-ms2 segundo os parâmetros de entrada que se apresentam para os dois modelos estudados (QUADRo IV).

De acordo com o QUADRo V as taxas de erosão medidas e previstas por ambos os modelos relativamente aos dois locais de monitorização encontram-se coerentes relativamente às pequenas diferenças entre as encostas. No entanto, o modelo USLE sobrestima as taxas de erosão, enquanto que o modelo MMF permite obter resultados mais fidedignos.
QUADRo IV - Valores de entrada nos modelos USLE e MMF para Açores-ms1 e Açores-ms2

\begin{tabular}{|c|c|c|c|c|}
\hline Modelo & Parâmetro & Açores-ms1 & & Açores-ms2 \\
\hline \multirow{3}{*}{ जू } & $\begin{array}{l}R \\
k \\
K\end{array}$ & & 2421,79 & \\
\hline & LS & 4,531 & \multirow{2}{*}{0,50} & 3,380 \\
\hline & $\begin{array}{l}c \\
p\end{array}$ & 100 & & 0.35 \\
\hline \multirow{8}{*}{ 岁 } & $\begin{array}{l}R \\
R n\end{array}$ & & $\begin{array}{l}1134,2 \\
1,73\end{array}$ & \multirow{6}{*}{15} \\
\hline & $\begin{array}{r}\mathrm{Rn} \\
1 \\
\end{array}$ & & $\begin{array}{l}173 \\
30\end{array}$ & \\
\hline & $\begin{array}{l}\text { MS } \\
\text { BD }\end{array}$ & & $\begin{array}{l}0,28 \\
1,2\end{array}$ & \\
\hline & $k$ & & $\begin{array}{l}0,09 \\
0,7 \\
2\end{array}$ & \\
\hline & $\begin{array}{l}S \\
A\end{array}$ & 21 & 0,10 & \\
\hline & $\begin{array}{l}E t / E 0 \\
\text { C (CXP) }\end{array}$ & 0,50 & \multirow{3}{*}{0,68} & \\
\hline & CC & & & \\
\hline & $\begin{array}{l}\mathrm{GC} \\
\mathrm{PH}\end{array}$ & $\begin{array}{l}0,37 \\
4,5\end{array}$ & & $0,0,23$ \\
\hline
\end{tabular}

QUADRo V - Valores das Taxas de Erosão anuais para Açores-ms1 e Açores-ms-2 segundo as parcelas abertas e a modelação com o USLE e o MMF

\begin{tabular}{|c|c|c|}
\hline Método & Açores-ms1 & Açores-ms2 \\
\hline Parcelas Abertas & 0,02 & 0,04 \\
\hline Modelação USLE & 17,00 & 19,11 \\
\hline Modelaçāo MMF & 0,13 & 0,03 \\
\hline
\end{tabular}

\section{Modelação em toda a área de estudo}

Para todas as áreas inventariadas foi atribuída uma classificação relativa de risco de erosão, numa primeira fase as áreas foram classificadas com base nos fenómenos de escala superior e posteriormente distinguidos com base nos fenómenos da micro escala. É de referir que devido a erros de interpretação de fotografias aéreas algumas encostas necessitaram de ser reclassificadas.

Nos resultados, pode-se verificar que as áreas detentoras da classificação do maior risco de erosão são ambas áreas lavradas (classes A5 e A1). É de salientar que todas as classes que são compostas por terraços (A3 e A4) se apresentam entre a classificação médio e médio alto segundo a validação de campo.

Foi então possível obter um mapa que retrata a presença de fenómenos erosivos de acordo com o inventário realizado (Fig. 3).

A modelação foi realizada para toda a área de estudo pelo USLE com base na aplicação dos factores referenciados no QUADRo IV, mas de acordo com a variação de cada encosta nos factores LS e $\mathrm{P}$, verificando-se uma elevada heterogeneidade (Fig. 4).

Realizou-se então uma comparação entre a classificação relativa das áreas inventariadas com as correspondentes segundo o modelo USLE (QUADRo VI).

Ao analisar esta correspondência (QUADRo VII), verifica-se uma grande disparidade de resultados pois apenas 5 de 25 encostas se apresentam com classificação relativa semelhante.

Quanto à modelação realizada para toda a área de estudo com base no MMF na aplicação dos factores referenciados no QUADRo IV, mas de acordo com a variação de cada encosta nos factores $\mathrm{S}, \mathrm{C}$ (que diz respeito ao produto de C por $\mathrm{P}$ do USLE), $\mathrm{PH}$ e GC pode-se verificar uma elevada 
QUADRo VI - Resultados do inventário de fenómenos erosivos de escala superior e respectiva classificação quanto ao risco de erosão.

\begin{tabular}{|c|c|c|c|c|c|}
\hline Classe - Transecto & Reclassificaçăo & $\begin{array}{c}\text { Rills } \\
\text { (presença) } \\
\end{array}$ & $\begin{array}{c}\text { Area transversal rill } \\
\text { (máximo verificado } \\
\text { cm2) }\end{array}$ & $\begin{array}{l}\text { Exposiçăă } \\
\text { de raizes } \\
\text { (presença) }\end{array}$ & $\begin{array}{l}\text { Classes de risco } \\
\text { de erosäo }\end{array}$ \\
\hline A7-tro06 & A5 & $x$ & 1495 & & \multirow{2}{*}{ Elevado } \\
\hline A2-tro01 & A1 & $x$ & 1275 & & \\
\hline A4-tro02 & A4 & $x$ & 507 & & \multirow{6}{*}{ Médio Alto } \\
\hline A8-tro11 & A6 & $\mathrm{x}$ & 424 & & \\
\hline A8-tro18 & A6 & $x$ & 375 & & \\
\hline A8-tro06 & A8 & $x$ & 162 & $\mathrm{x}$ & \\
\hline A8-tro04 & A8 & $x$ & 125 & $\mathrm{x}$ & \\
\hline A6-tro08 & A6 & $x$ & 34 & $x$ & \\
\hline A4-tro03 & A3 & $\bar{x}$ & $\begin{array}{l}\text { Reduzido } \\
\end{array}$ & $x$ & \multirow{6}{*}{ Médio } \\
\hline A3-tro02 & A4 & $\mathrm{x}$ & Reduzido & & \\
\hline A4-tro05 & A4 & $\mathrm{x}$ & Reduzido & & \\
\hline A4-tro06 & A4 & $\mathrm{x}$ & Reduzido & & \\
\hline A8-tro03 & A8 & $\mathrm{x}$ & Reduzido & & \\
\hline A8-tro08 & A6 & $x$ & Reduzido & & \\
\hline A1-ms1 & A8 & & & $\mathrm{x}$ & \multirow{2}{*}{ Médio Baixo } \\
\hline A7-tro02 & A7 & & & $x$ & \\
\hline A2-ms2 & A6 & & & & \multirow{9}{*}{ Baixo } \\
\hline A2-tro05 & A1 & & & & \\
\hline A6-tro03 & A6 & & & & \\
\hline A6-tro04 & A1 & & & & \\
\hline A6-tro07 & A6 & & & & \\
\hline A7-tro05 & A7 & & & & \\
\hline A7-tro08 & A5 & & & & \\
\hline A8-tro05 & A8 & & & & \\
\hline A8-tro09 & A8 & & & & \\
\hline
\end{tabular}

heterogeneidade, não só entre as diversas encostas mas também ao longo delas (Fig. 5). Também se verifica que as ordens de grandeza das taxas de erosão são muito inferiores às do modelo anterior, de tal forma que toda a área de estudo apresentaria segundo o mapa do USLE (Fig. 4) uma classificação de risco baixo de erosão.

$\mathrm{Na}$ tentativa de adoptar a mesma metodologia que foi aplicada no modelo USLE procedeu-se à análise de correspondência entre a classificação com origem na validação de campo e a classificação derivada do modelo MMF, mas desta vez com base na classificação de risco máximo verificado nas várias encostas, visto que neste caso é apresentada a variabilidade do risco ao longo de cada uma.

QUADRO VII - Correspondência entre classificação originada pela validação de campo e pela modelação com o US

\begin{tabular}{|c|c|c|c|c|c|c|}
\hline \multirow{2}{*}{\multicolumn{2}{|c|}{$\begin{array}{l}\text { Correspondência } \\
\text { (nº encostas) }\end{array}$}} & \multicolumn{5}{|c|}{ Modelo USLE } \\
\hline & & Elevado & Médio Alto & Médio & $\begin{array}{l}\text { Médio } \\
\text { Baixo }\end{array}$ & Baixo \\
\hline \multirow{4}{*}{$\begin{array}{l}\text { Validaçăo } \\
\text { de Campo }\end{array}$} & Elevado & 0 & 0 & 1 & 0 & 1 \\
\hline & Médio Alto & 1 & 2 & 2 & 0 & 0 \\
\hline & $\begin{array}{l}\text { Médio } \\
\text { Médio }\end{array}$ & 1 & 1 & 0 & 1 & 3 \\
\hline & $\begin{array}{l}\text { Médio Baixo } \\
\text { Baixo }\end{array}$ & $\begin{array}{l}1 \\
3 \\
\end{array}$ & $\begin{array}{l}1 \\
0\end{array}$ & $\begin{array}{l}0 \\
2\end{array}$ & $\begin{array}{l}0 \\
1\end{array}$ & $\begin{array}{l}0 \\
3\end{array}$ \\
\hline
\end{tabular}

De acordo com a análise feita, os resultados voltam a apresentar uma grande disparidade, apresentando 3 de 25 encostas coerentes com a validação de campo (QUADRo VIII). No entanto, é de referir que esta comparação pode não ser a mais adequada porque este modelo apresenta taxas de erosão muito baixas para a formação dos fenómenos erosivos verificados no local.

QUADRO VIII - Correspondência entre classificação originada pela validação de campo e pela modelação com o MMF

\begin{tabular}{|c|c|c|c|c|c|c|}
\hline \multirow{2}{*}{\multicolumn{2}{|c|}{$\begin{array}{l}\text { Correspondência } \\
\text { ( } n^{\circ} \text { encostas) }\end{array}$}} & \multicolumn{5}{|c|}{ Modelo MMF } \\
\hline & & Elevado & Médio Alto & Médio & Médio Baixo & Baixo \\
\hline $\begin{array}{l}\text { Validaçăo } \\
\text { de Campo }\end{array}$ & $\begin{array}{l}\text { Elevado } \\
\text { Mediodito } \\
\text { Médiodo oixo } \\
\text { Maixaxo }\end{array}$ & & & & & $\begin{array}{l}1 \\
1 \\
0\end{array}$ \\
\hline
\end{tabular}

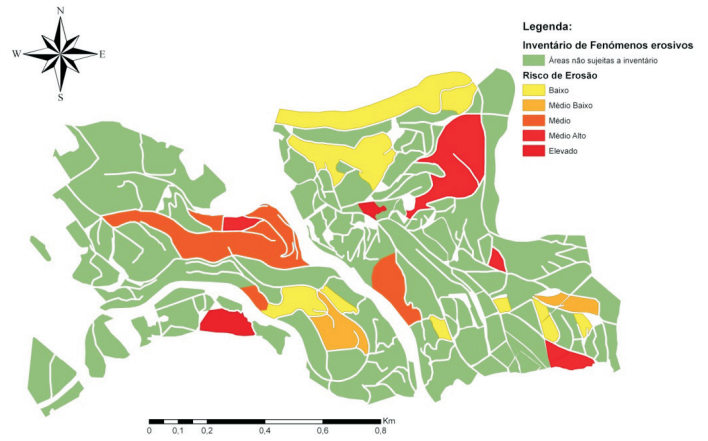

Fig. 3 - Classificação de fenómenos erosivos com base nos inventários realizados na área de estudo.

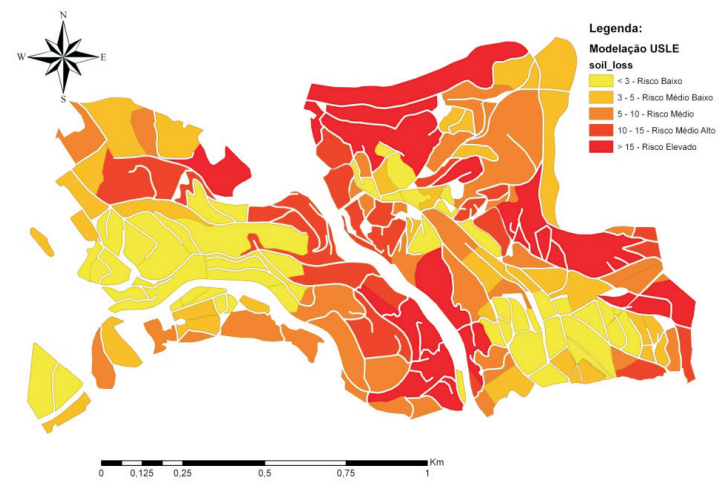

Fig. 4 - Resultados de taxas de erosão e correspondente risco obtidos na modelação com USLE em toda a área de estudo.

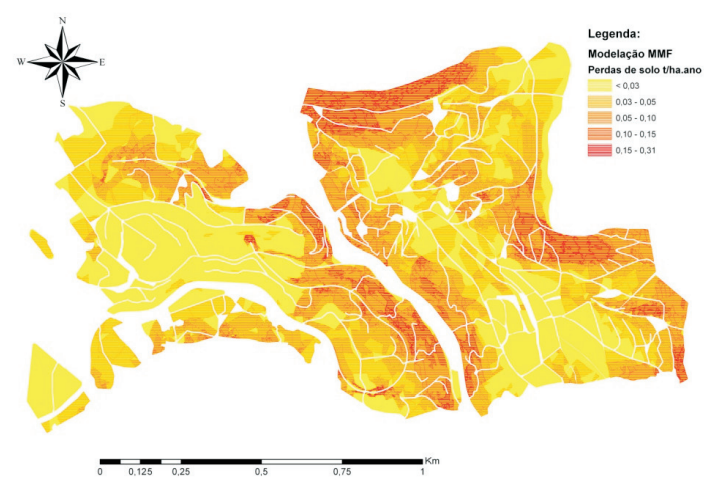

Fig. 5 - Resultados de taxas de erosão e correspondente risco obtidos na modelação com MMF em toda a área de estudo.

Com vista a verificar se o MMF apresenta uma relação com o modelo anterior compararam-se os resultados de ambos nas várias encostas quanto às taxas de erosão determinadas, em que, no caso do MMF, por apresentar uma variabilidade em cada encosta, foi avaliada pela média ponderada dessas taxas (Fig. 6) e pelo máximo verificado em cada encosta. Em ambos os casos, é visível uma elevada correlação de resultados $(0,85$ e 0,74), o que indica que as modelações realizadas identificam riscos nos mesmos locais ainda que de uma ordem de grandeza diferente. 


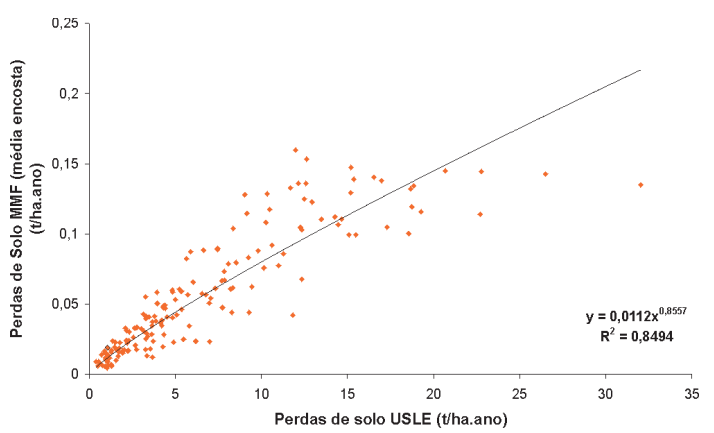

Fig. 6 - Taxas de erosão segundo os modelos MMF vs USLE.

\section{Discussão}

\section{Simulações de chuva e parcelas de erosão}

Os resultados das simulações de chuva em valores absolutos, mesmo em várias ocasiões durante o ano hidrológico, mostram taxas de escorrência e erosão diferentes das medidas à escala da encosta, logo não se apresentam como a melhor forma de obter estimativas de erosão. Vários aspectos poderão justificar este facto. A intensidade de precipitação das simulações é muito superior à verificada no campo (45 e $80 \mathrm{~mm} / \mathrm{h}$ vs I30máx verificado $37 \mathrm{~mm} / \mathrm{h}$ ). Outro, diz respeito à escala em que se encontram, pois como uma está à escala da encosta e outra à micro-escala, possuem respostas hidrológicas diferentes. Pois o fluxo superficial é descontínuo e, como tal, a escorrência diminui com o aumento do comprimento da encosta ou da escala estudada (Goml et al., 2008).

Não se podem aplicar os modelos para as condições de simulação de chuva, devido a vários factores. Os dois modelos estudados foram desenvolvidos para serem aplicados apenas à escala da encosta com uma base anual e porque a equação de energia cinética tem por base uma calibração segundo eventos naturais de precipitação, com uma carga energética superior à das simulações.

Os resultados de taxas de erosão e escorrência medidos à escala de encosta permitem verificar que não existem diferenças significativas nas duas encostas estudadas. Também é de referir que determinações de taxas de erosão como o caso das parcelas abertas com valores consideravelmente baixos não permitem uma diferenciação de dois locais devido ao erro inerente à sua determinação. Isto significa que o erro incutido na determinação dessas taxas de baixo valor é muito elevado, aliás impraticável, segundo NEARING et al. (1999), que também afirma que pode não existir muito interesse em diferenciar características dos locais quando as taxas de erosão não apresentam um valor relevante.

O motivo pelo qual as taxas de erosão são bastante reduzidas deve-se ao facto de o próprio local não possuir grandes quantidades de solo disponível, pois trata-se de uma área bastante erodida no passado, apresentando também por isso, um coberto de pedras bastante elevado que confere uma protecção contra a precipitação e escorrência.
Modelação à escala da encosta

Quando comparados os dois modelos estudados com as medições de taxas de erosão, não se verificam diferenças relevantes entre as duas parcelas estudadas. 0 modelo MMF apresenta uma maior viabilidade de resultados por se aproximar à ordem de grandeza das taxas de erosão reais, enquanto que o USLE sobrestima estas mesmas. No entanto, é de referir que muitos dos parâmetros utilizados no MMF consistem em aproximações, podendo assim perder assim algum rigor, devido à não possibilidade de recolher tais dados no local.

No caso do USLE uma melhor parametrização do factor $C$ poderia produzir melhores estimativas. A utilização de um valor na ordem de 0,05 como foi proposto por LARSEN e Macdonald (2007). Para áreas ardidas de severidade moderada, aproxima estas estimativas às taxas reais. É de referir que o factor $\mathrm{P}$ utilizado para Açores-ms2 de 0,35 pode não ser o mais adequado, visto que a intervenção realizada não proporciona conservação de solo, pelo contrário uma lavragem no sentido do declive apenas piora o risco de erosão sendo o valor de 1 então o mais adequado.

\section{Modelação em toda a área de estudo}

Verificou-se que em ambos os modelos a correspondência relativa de classes de risco quando comparada com a validação de campo não proporciona resultados fidedignos. Tais discrepâncias poderão dever-se a vários aspectos.

Uma inadequada parametrização do factor P poderá estar na origem desses erros, tal como, por exemplo, a consideração de que terraços seriam práticas de conservação do solo eficazes, e, no entanto, segundo a validação de campo, tal facto não acontece. Verificou-se também que, em ambos os casos, a correspondência de classes aumenta com a utilização de um factor $\mathrm{P}$ de 1 para toda a área de estudo.

É de referir que esta validação foi realizada de forma aleatória em 32\% da área de estudo, logo, uma comparação de um número superior de encostas providenciaria uma maior fidelidade de resultados.

Da comparação dos resultados segundo os dois modelos resultou uma correlação elevada, ainda que para o MMF vários parâmetros de entrada do modelo necessitassem de ser estimados, por não existir a possibilidade de recolha de tais dados no local de estudo. É de referir também que a ordem de grandeza das perdas do solo se aproxima mais às medições efectuadas no campo.

O motivo pelo qual esta correlação é elevada deve-se ao facto de que estes resultados assentam na formulação do MMF e são relativos à capacidade de transporte da escorrência, e não à capacidade de desagregação do solo da precipitação e escorrência. Indirectamente entram no cálculo pelo modelo USLE. 


\section{Conclusões}

A validação do USLE e do Morgan-Morgan-Finney pelas diferentes metodologias de medição de taxas de erosão permitiu uma avaliação em diferentes escalas, apresentando-se o MMF como o modelo mais viável na determinação das taxas de erosão, ainda que apresente uma classificação espacial ao mesmo nível que o USLE, com baixa correspondência.

Uma melhor parametrização dos factores de entrada em ambos os modelos poderá aproximar estes resultados à realidade, visto que se verificaram erros na escolha do factor $\mathrm{P}$ na área de estudo.

Propõe-se um estudo mais aprofundado no âmbito da validação do modelo MMF, e da sua nova versão (MORGAN E Duzant, 2008), num maior conjunto de áreas para diferentes condições de solo e clima.

\section{Agradecimentos}

Este estudo foi realizado no âmbito do projecto EROSFIRE (POCI/AGR/60354/2004), financiado pela Fundação para a Ciência e Tecnologia de Portugal (FCT) e co-financiado pela FEDER através do programa POCI2010.

Um agradecimento a todas as pessoas envolvidas no projecto EROSFIRE, que permitiram a recolha de dados de campo, laboratório e de uma ou outra forma contribuíram para a realização deste trabalho.

\section{Referências bibliográficas}

Brandão, C.; Rodrigues, R.; PInto da Costa, J. (2001) - “Análise de fenómenos extremos - precipitações intensas em Portugal Continental”. Direcção dos Serviços de Recursos Hídricos, Lisboa, Instituto da Água.

Cerdá, A.; Ibáñez, S.; Calvo, A. (1997) - “Design and operation of a small and portable rainfall simulator for rugged terrain". Soil Technology, 11 (2), p. 161-168.

DRA-CENTRO (Direcção Regional do Ambiente do Centro) (1998) - "Plano de bacia hidrográfica do Rio Vouga, $1^{\text {a }}$ fase, Análise e diagnóstico da situação de referência” Análise biofísica, Anexos. Lisboa.

FAO (1988) - "Soil Map of the World". World Soil Resources Report 60. FAO. Rome.

Ferreira, A.J.D. (1996) - Processos Hidrológicos e hidroquímicos em povoamentos de Eucalyptos globulus labill e Pinus pinaster Aiton, Tese de Doutoramento, Universidade de Aveiro.

Gomi, T.; Sidle, R.C.; Miyata, S.; Kosugi, Onda, Y. (2008) -
"Dynamic runoff connectivity of overland flow on steep forested hillslopes: Scale effects and runoff transfer". Water Resourses Research, vol. 44, W08411.

INAG (2003) - Perdas de solo após incêndios florestais do Verão de 2003. Lisboa, Instituto de Água.

INAG (2005) - Avaliação e minimização de riscos de erosão em zonas afectadas por incêndios florestais. Lisboa, Instituto de Água.

LaRsen, I J.; Macdonald, L.H. (2007) - "Predicting post-fire sediment yields at the hillslope scale: Testing RUSLE and Disturbed WEPP”. Water Resources Research. 43, W11412.

LUCENA, J.M.M. (2006) - Características hidráulicas de suelos en eucaliptares recientemente ardidos en la zona Centro de Portugal. Traineeship report, Coimbra, Escola Superior Agrária de Coimbra.

Morgan, R.P.C. (2001) - "A simple approach to soil loss prediction: a revised Morgan-Morgan-Finney model”. Catena, 44, p. 305-322.

Morgan, R.P.C.; Duzant, J.H. (2008) - "Modified MMF (Morgan-Morgan-Finney) model for evaluating effects of crops and vegetation cover on soil erosion". Earth Surface Processes and Landforms, 32, p. 90-106.

NeAring, M.A.; Govers, G.; Norton, L.D. (1999) - "Variability in Soil Erosion Data from Replicated Plots". Soil Sci. Soc. Am. J, 63, p. 1829-1835.

Puigdefábregas, J. (1998) - "Ecological impacts of global change on drylands and their implications for desertification". Land Degrad. Develop., 9, p.393-406.

SAnto, F.E. (2006) - "Caracterização Climática - Ano Agrícola 2005/2006”. Boletins e Relatórios do Instituto de Meteorologia, I.P.

SHAKESBY, R.A.; Doerr, S. H. (2006) - "Wildfire as a hydrological and geomorphological agent". Earth-Science Reviews. 74: 269-307.

WischmeIER, W.H.; SMITH, D.D.(1978) - "Predicting rainfallerosion losses- a guide to conservation planning". Agriculture Handbook. N N537. USDA. Washington, D.C; 58.

\section{Referências na Internet}

PimentA, M.T. (1999) - Directrizes para a Aplicação da Equação Universal de Perdas dos Solos em SIG. Factor de Cultura, C, e Factor de Erodibilidade do Solo, K, [pdf], http://snirh.pt. [2008]. 